\title{
Una década de periódicos en Internet: estrategias documentales
}

\author{
Juan Carlos Marcos Recio
}

Universidad Complutense de Madrid (España)

\section{Resumen}

Se ofrece un estudio con motivo de la primera década de los periódicos digitales en Internet, en el que se recogen los planteamientos documentales empleados en la elaboración y tratamiento de la información. Se postulan estrategias y se analizan los métodos documentales que se emplean en los periódicos más importantes que tienen presencia en Internet y en las publicaciones independientes que se elaboran mediante un número muy corto de redactores y documentalistas. La relación entre periodistas y documentalistas se ha estrechado gracias a la revolución digital. El archivo de noticias se postula como un importante producto comercial de los portales periodísticos.

Palabras clave: Periódicos digitales. Internet. Información digital. Metodología documental. Inversiones.

\section{Abstract}

On the occasion of the tenth anniversary of the digital newspapers on Internet, a study is offered which covers the documentary approaches used in the elaboration and processing of news and information. Strategies are formulated and an analysis is offered of the documentary methods that are employed by the most important newspapers present on Internet and by the independent publications which are published by a very limited number of editors, writers and researchers. The relation between journalists and documentalists has become stronger with the digital revolution. The digital news archives is postulated as an important commercial product for newspaper portals.

Keywords: Digital newspapers. Internet. Digital information. Documentary methodology. Investments.

\section{Introducción}

A lo largo del siglo XX se producen multitud de avances en la comunicación, especialmente en la última década, en la que se desarrollan nuevas formas de presentar y sobre todo más velocidad a la hora de enviar y recibir la información.

Scire. $11: 2$ (sep.-dic. 2005) 63-77. ISSN 1135-3761. 
Durante ese siglo, los medios de comunicación han sido los protagonistas no solo porque son un espejo en el que se mira la sociedad, sino porque consiguen cada vez más acercar las diferentes sociedades y, dentro de ellas, a los individuos que las componen. No hay civilización sin una actividad comunicativa diaria, aunque en ocasiones los propios medios de comunicación se vean envueltos en situaciones comprometidas, como la transmisión de imágenes de conflictos en los que la vida de las personas no parece tener valor. Pero el proceso comunicacional ha cambiado considerablemente en los tiempos más recientes. Ejemplo significativo de ese cambio son los propios medios de comunicación. Lo que antes necesitaba casi un siglo para asentarse, ahora en apenas una década llega y se establece como actividad principal. Eso es lo que ha sucedido con Internet, ese punto de encuentro para millones de personas que siguen creyendo en la información que publican los periódicos digitales, aunque ahora tengan más opciones de información, desde los sitios webs personales, las bitácoras, los organismos oficiales y cada uno de los lugares que ofrecen información variada.

El presente trabajo pretende dar una visión actual de cómo están los medios de comunicación en Internet, después de una década mayoritaria dentro de la red de redes. Además, se estudian las herramientas documentales con las que cuentan estos medios de comunicación. El objetivo fundamental es dar información de actualidad, pero la documentación no era ajena a los medios cuando llegó Internet. Necesitó una transformación que en algunos medios aún se está acometiendo en la actualidad. Como sucede con frecuencia, las técnicas documentales van por detrás de lo que ofrecen los medios, puesto que su razón de ser es conseguir que la información llegue a tiempo, independientemente de que esté mejor o peor preparada. Es necesario recordar aquí que el tiempo juega un papel decisivo en los periódicos en Internet y ese tiempo es el que se necesita a veces para mejorar documentalmente la información.

Hay, pues, un hecho diferenciador entre lo que es información de actualidad, que ha de cambiarse con relativa celeridad, y la información reposada, ampliada y comentada por especialistas, en la que la documentación puede aportar los recursos necesarios para hacer más creíble y veraz esa información. En este caso, el uso de diversas fuentes de información sería la garantía que el lector necesita para seguir confiando en ese medio de comunicación. La aplicación de estos cambios en los periódicos digitales se ha realizado sin una aplicación práctica. La información llega a los periódicos y estos no disponen de tiempo para mejorarla. Se ha entrado, en ocasiones sin quererlo, en una dinámica en la que lo único significativo es que esté en el periódico unos segundos antes que en su competidor, sin importar muchas veces si esa información es verdad o si se aproxima a la verdad. La justificación es sencilla: quien llega primero es luego el más leído y quien más lectores tiene más publicidad consigue. Si una parte importante de los periódicos di- 
gitales sobrevive gracias a la publicidad, el razonamiento es claro: conseguir lectores a toda costa. Sin embargo, a largo plazo los resultados indican otra realidad. Algunos periódicos que apostaron por Internet y por ser los primeros en informar ya han desaparecido. Informar sí, pero contrastando las fuentes y valorando con expertos algunos de los contenidos que publican los periódicos digitales.

\section{Periódicos digitales: orígenes en España}

La información que contienen los periódicos sigue siendo el motor que mueve la sociedad desde el ámbito político, económico, social, religioso, etc.; de ahí la importancia que han tenido siempre los medios de comunicación. A lo largo de la historia ese control se fue haciendo más estrecho, ya que los grupos de poder, tanto político como económico, se fueron haciendo con su titularidad. Sin embargo, con la llegada de Internet ese poder es más difuso, ya que cualquiera puede publicar en Internet; cualquiera que disponga de un ordenador y una línea de conexión ya está en el ciberespacio. Esta situación ha ido cambiando en los últimos años. Cierto es que la red puede ofrecer una libertad mayor, pero al final han sido los grandes grupos de comunicación quienes han atraído hacia sus páginas a la gran mayoría de lectores, ofreciendo un producto informativo competente y, sobre todo, gratis, frente a otros pseudoperiódicos que contienen información pero escasa opinión; o, al menos, la opinión de expertos en un área concreta.

Se requiere, por tanto, situar esa realidad. Aunque el objeto de este trabajo es analizar la última década de los periódicos digitales, que coincide con su mayor desarrollo, el origen de los periódicos electrónicos — entonces —, digitales - hoyestá en la década de los setenta. Lo mismo que Internet en la última década ha cosechado su gran explosión, sin embargo sus orígenes se remontan varias décadas atrás. En el caso de los periódicos electrónicos, Armentia, Elexgaray y Pérez proponen en su libro Diseño y periodismo electrónico que el primer periódico del mundo en soporte electrónico se puso en marcha en Birmingham en marzo de 1979. Se trataba del Viewtel 202, que se consideraba como un servicio complementario del Birmingham Post and Mail y cuyas páginas se transmitían por el sistema prestel de teletexto. El servicio funcionaba doce horas al día, de lunes a sábado. En el caso español, es común la aceptación por parte de los estudiosos que la revista valenciana El Temps fue la primera que puso en marcha una edición digital, a la que siguieron varios periódicos catalanes, pioneros en España de los medios de comunicación en Internet: La Vanguardia, El Periódico de Catalunya y Avui. Fue en 1994 cuando esta revista cultural —El Temps — se colocó en Servicom, y más tarde pasó también a Internet.

Bien es cierto que, desde comienzos de los años noventa, ya algunos periódicos estaban preparando sus ediciones para sacarlas en Internet. Contaban con la ventaja de que una parte o la totalidad del periódico ya se hacía en digital, puesto que

Scire. 11 : 2 (sep.-dic. 2005) 63-77. ISSN 1135-3761. 
se pasaba a un CD-ROM para comercializarla. Uno de estos medios fue $\mathrm{El} \mathrm{Pe-}$ riódico de Catalunya, que, gracias al trabajo de su director técnico, Mario Santinoli, consiguió estar pronto en Internet, en relación con otros periódicos de tirada nacional. En 1992, Barcelona era una ciudad referente en todo el mundo. Tenía una cita con los Juegos Olímpicos de Verano. Algunos medios aprovecharon el tirón y la publicidad que esos Juegos traían. En el caso de El Periódico se apostó por un proyecto conjunto para elaborar un producto digital — periódico — en el que la información, la publicidad, los recursos económicos y la tecnología se daban la mano: Proyecto NewsPad (1).

En este proyecto, los "hermanos" de El Periódico fueron Acorn Computer (de Cambridge), quien se encargó de suministrar de tecnología; la firma francesa Carat, intermediaria de las empresas publicitarias con una fuerte implantación en Europa, que lleva el control del impacto de la publicidad sobre los usuarios; el Institut Català de Tecnologia, que aporta apoyo técnico y resuelve las consultas sobre telecomunicaciones, y la empresa griega Archimedes Ltd. Este proyecto ofrece sobre todo una nueva forma de plantear la información, buscar recursos para gestionarla — publicidad — y mostrar el camino a la tecnología necesaria para hacerlo y recibirlo. Si bien el proyecto se quedó en eso, un proyecto, luego sirvió para otros muchos periódicos digitales que tomaron como referencia algunas de las cosas allí creadas.

A comienzos de los noventa, las empresas periodísticas ven lejano el día en que tendrán que hacer frente a un soporte digital. Una gran mayoría ni siquiera se plantea esas opciones, puesto que el negocio impreso les permite creer que durante varios años seguirá siendo rentable. Por el contrario, tan solo un número muy reducido de empresas — más bien algunas personas dentro de ellas— se plantean crear soportes digitales que transmitan informaciones. Los primeros ensayos empiezan hacia 1994. Se trata de hechos aislados, llevados a cabo fundamentalmente desde el departamento de informática e infografía de los periódicos. Aquí es donde está el germen, el origen y el comienzo de los primeros periódicos digitales, confeccionados, creados y llenos de la información que salía en la versión impresa. Estos primeros ensayos van apareciendo en pruebas, como si de números cero de una nueva publicación se tratara. No hay un espíritu colectivo por hacer una publicación final. Más bien son informaciones colocadas en las secciones habituales del periódico impreso. Sin embargo, se necesita una nueva portada, una mirada nueva para los lectores que buscan en el periódico digital informaciones más dinámicas, ágiles y sobre todo actualizadas.

¿Qué ofrecen estos primeros periódicos? ¿Qué tipo de informaciones tienen? ¿Quién se encarga de actualizarlas? Visto con la perspectiva de una década, se puede determinar que era mucha la información que entonces ofrecían, y muy escasa si se hace un estudio comparativo con los contenidos actuales. Las informa- 
ciones apenas seguían un orden dentro de la portada, ya que esta presentaba una configuración multifuncional, en la que la publicidad y las imágenes se convertían en el centro de la información. Como entonces no había una infraestructura informativa creada y la actualización de la información no se hacía, las primeras informaciones digitales tenían la misma duración que la de los periódicos impresos, es decir, una única edición duraba todo el día. Con posterioridad, se fue recortando ese tiempo y se pasó a ofrecer una o dos actualizaciones, hasta la llegada de las informaciones en tiempo real, ya metidos dentro del siglo actual. Ahora, la competencia no es tan solo llegar el primero, sino dar varias versiones de la misma información, completar las diversas vertientes que puede presentar una información.

Sin embargo, los esfuerzos de algunos ensayos, como el Proyecto NewsPad, sembraron el conocimiento para que algunos profesionales tomaran como un conjunto de actividades la información digital. No es una publicación digital si no ofrece contenidos informativos, apoyados en recursos y fuentes digitales, con una actualización constante y con una fuente de financiación propia que le permita ser independiente. En este sentido, desde El Periódico de Catalunya se hizo un esfuerzo para mostrar en aquellos comienzos cómo se podría presentar la información dentro de un medio digital y como tendría que ser esta. A juicio de Santinoli, en esos momentos se requería (2)

[Una] transformación del ordenador en lo que los americanos definen text top, una herramienta que reúna todos los elementos que necesita el periodista para trabajar, es decir, que el periodista necesita documentarse, acceder al archivo de fotografía, una agenda, etc., y todo esto dentro del ordenador para comunicarse con el mundo externo.

\section{La información cambia con el siglo}

A finales del siglo XX, la mayoría de los periódicos con cabeceras impresas tenían presencia en Internet. Además, su labor no se centraba ya en mostrar sus contenidos, sino que se había producido una revolución tecnológica adaptada a las necesidades informativas. Para lograrlo fue necesaria una importante mejora en los servicios tecnológicos (adaptación a Internet); nuevos planteamientos en el diseño y la composición; junto a la información, más servicios; ampliar la consulta desde la hemeroteca a más números y un cambio significativo en redacción y en el centro de documentación para dar valor a la información no solo a lo largo del día, sino también de cara al futuro.

Con cierta frecuencia se piensa que la tecnología avanza de forma paulatina. No es cierto. En el momento histórico que se estudia, ese avance fue significativo. Con el cambio de siglo se van produciendo nuevas informaciones que afectan de forma directa a la documentación. La más importante es el volumen de producción. Hasta entonces, la mayoría de los periódicos digitales redactaba y publicada una única edición. Por tanto, los contenidos eran muy similares a los que

Scire. 11 : 2 (sep.-dic. 2005) 63-77. ISSN 1135-3761. 
tenían los periódicos impresos. Se plantea entonces una duda importante para los editores: no se puede ofrecer lo mismo gratis en Internet, cuando hay suscriptores y lectores que pagan por la versión impresa. ¿Cómo solucionar esta situación? La respuesta estaba en las secciones que recibiría cada medio. Así, el periódico impreso seguía con todos sus contenidos y el digital solo ofrecía una parte de las secciones. Sin embargo, no fue suficiente.

Frente a una competencia feroz de otros medios digitales, añadida a la tradicional rivalidad entre los periódicos impresos que habían apostado por versiones en Internet, entra en acción la tecnología para dar un sentido nuevo a las publicaciones dentro de la Red. El primer empuje serio se produce con la actualización de la información. En efecto, Internet permite hacer el seguimiento de la información en el mismo momento en que se produce y ofrecer datos cada vez que hay un cambio. En segundo lugar, se mejora todo el proceso cuando una serie de periódicos digitales apuestan por la introducción de informaciones sin tener en cuenta el tiempo. Junto a secciones fijas, la portada del periódico digital ofrece una rueda de contenidos informativos en la que van apareciendo los cambios producidos en las informaciones que ya están publicadas. Y, en tercer lugar, todo el proceso se ejecuta de forma dinámica, es decir, ofreciendo aspectos significativos de la información, algo impensable en los periódicos impresos.

Algunos ejemplos de esta nueva realidad sería la información que cada año genera la entrega de los Oscar de cine. Por diferencia horaria con Estados Unidos, la mayoría de los periódicos impresos ya han cerrado sus ediciones cuando se conocen los resultados. La radio, a la mañana siguiente, informa de los ganadores y perdedores. Cuando el lector se acerca al periódico veinticuatro horas después descubre que una gran parte de la información ya no le interesa. En Internet, se puede seguir en directo la transmisión y paralelamente ir ofreciendo en el periódico digital esa información. Otro ejemplo tendría que ver con la sección de sucesos. Ante cualquier catástrofe, cuando los medios impresos cierran edición, en la mayoría de los casos indican un número de heridos y fallecidos, así como informaciones sobre daños materiales. A la mañana siguiente, cuando el lector se enfrenta a la información la realidad ha cambiado significativamente. Aquí radica parte del éxito de los medios digitales, que pueden ir actualizando los datos y el lector tiene información más reciente porque el seguimiento de los hechos noticiosos es más cercano. Tras la actualización llegaron las mejoras del diseño, la presentación de la información y la abundancia de servicios con el fin de hacer un producto de calidad en la información y que además fuera capaz de aportar recursos financieros para que la empresa editorial pudiera mantenerse, sobre todo en épocas en las que la publicidad en Internet atraviesa momentos delicados.

Pero ¿qué pasa en la actualidad? La información es algo cambiante, no solo en sus contenidos sino también en la forma de presentarlos y entregarlos. El lec- 
tor/usuario digital se ha acostumbrado a sistemas de información que complementan los contenidos de actualidad que ofrecen los periódicos en Internet. Se trata de los conocidos blogs, sitios de Internet donde el lector encuentra información con mayores contenidos que en las publicaciones digitales y en los que puede participar. No es un fenómeno nuevo, puesto que ya vienen funcionando con regularidad desde hace cinco años, pero sí han conseguido atrapar a millones de lectores/visitantes de Internet. Algunos datos, apuntados por Olalla Novoa (2005) en elmundo.es, pueden ilustrar la situación actual:

Cada día se suman 80.000 nuevos weblogs, o bitácoras, a los más de 31 millones que ya pueblan Internet. Lo que se inició como un mero diario personal en la Red ha ido adquiriendo fuerza hasta llegar a convertirse en una fuente cada vez más presente en una sociedad que demanda más información y con mayor inmediatez.

La aparición de los blogs fue fruto de una situación atípica para la mayoría de los medios de comunicación, que se vieron impotentes ante la avalancha de información que se generó tras los atentados del 11 de septiembre. Así, por primera vez en la historia de la comunicación fue posible ver imágenes e información del avión que se estrelló contra el Pentágono antes de que salieran en el resto de los medios de comunicación. Como tantas otras cosas, el 11-S. supuso para los medios de comunicación otra manera de enfrentarse a la información. Y luego, durante la guerra de Irak, muchos periodistas obtuvieron información de cuadernos de bitácora realizados por personas que vivían en el país, al que no tenían acceso los periodistas. Sin embargo, desde el punto de vista de la documentación queda por resolver un aspecto importante: ¿Cómo y quién contrasta la información? ¿Se consultan fuentes para su publicación? En la mayoría de los casos no. Se trata de contar historias, muy personales en la mayoría de los casos, o de terceros que deciden aportar contenidos al blog, pero la información ha de ser sobre todo real y veraz, y sin documentación, sin la consulta de fuentes, sin contrastar los datos, será muy difícil precisar que lo que se publica en los blogs es información periodística.

Un ejemplo reciente, publicado en Periodista Digital (http://www.periodistadigital.com), ayuda a situar la realidad de los blogs frente al periodismo digital, que está teniendo problemas para conseguir lectores, visitantes de su sitio web y consecuentemente un mayor incremento en la publicidad. Según Elena de Regoyos (2005), un blog brasileño se ha convertido en la referencia política y periodística: "De 156.000 visitantes únicos al mes a más de 1.700 .000 en tan solo un año. El secreto: buenas dotes narrativas, reputación periodística y una crisis política que analizar diariamente. Ricardo Noblat pasó de escribir una columna semanal a ser el bloguero periodístico más solicitado por los lectores brasileños, ávidos de conocer su análisis de la crisis que envuelve al Gobierno de Lula. Con la crisis su blog bate récords de audiencia y tiene una enorme repercusión en los medios periodístico y político". ¿Qué significado tiene esto? Que los medios han de ofrecer Scire. 11 : 2 (sep.-dic. 2005) 63-77. ISSN 1135-3761. 
alternativas, informaciones bien documentadas y de calidad para competir con estos sitios de Internet. En caso contrario perderán influencia social y política, y con ella, lectores y su principal fuente de recursos: la publicidad.

Pero no todos caminan en la misma dirección. Algunos expertos consideran que este tipo de información servirá para que el periodismo renazca. Se están ofreciendo nuevas visiones de la información que van más allá del periodismo tradicional. A juicio del secretario general de la Federación Internacional de Periodistas (FIA), citado por Olalla Novoa (2005), este tipo de informaciones no desbancará a los medios tradicionales, sino que les ayudará porque abre el campo a los pocos grupos de comunicación que controlan la información:

"Lo que sí ha hecho, y es fantástico, es generar por primera vez un debate sobre si el periodismo actual le está dando a la gente lo que quiere", insiste White, en un momento en el que la concentración empresarial en el sector ha favorecido que la información, a nivel mundial, esté en realidad controlada por muy pocas manos. Los blogs y el periodismo no se contraponen. Al contrario, propician el "renacer" del periodismo.

Este debate, que se alarga ya más de una década, no tiene que alejar al periodista de su trabajo de cada día, ejecutado con rigor informativo, veracidad, uso de las fuentes de información y contrastando las informaciones en el centro de documentación. Mientras estas reglas se respeten, no importa el medio por el que se transmita, al final será una información de calidad que dará un servicio a los usuarios.

\section{Estrategias documentales: un valor en alza}

Esa confusión general, ese estado de ánimo y esa rapidez de la información no han ayudado demasiado a la documentación. Una de las razones de ser de los medios es la conservación de su propia memoria. Quedó claro durante siglos, cuando los periódicos impresos almacenaban sus ediciones y las de la competencia para elaborar futuras informaciones ya que la capacidad de memoria en los seres humanos es limitada. Luego llegaron los ordenadores, y con ellos las bases de datos. Se mejoró entonces la rapidez de respuesta documental, aunque los medios tardaron en darse cuenta del uso y beneficio de tener bases de datos. Por otra parte, el proceso de creación, gestión y actualización conlleva unos recursos y gastos que no todos los medios podían asumir.

Con posterioridad, el proceso de realización de los periódicos pasa de impreso a digital. Durante algún tiempo, se hacen periódicos con métodos digitales, pero se publican impresos. Pero el auge de Internet sirve para atraer a lectores jóvenes, justo en un momento de crisis en los periódicos. Entonces se elabora y se publica la información digital. Este paso es importante para la documentación, que deja a un lado las carpetas y archivos en los que guardaba las fotografías y los artículos más interesantes para pasar a plantear nuevas tareas documentales. El documentalista de información electrónica se enfrenta de esta forma a un reto nuevo:

Scire. $11: 2$ (sep.-dic. 2005) 63-77. ISSN 1135-3761. 
gestionar con eficacia la información que se genera en su medio digital; valorar la información de otros medios digitales; elaborar dosieres informativos sobre contenidos históricos; adentrarse en la red y desentrañar lo que tiene valor y lo que no lo tiene; evaluar, aun a riesgo de equivocarse, la información que circula por las redes y que no está respaldada por organismos oficiales y adelantarse mediante el estudio y la observación a las necesidades del periodista que no puede perder tiempo acudiendo a sitios de Internet que no le aportan nada. Se trata de una tarea que permite filtrar y separar lo óptimo de lo que no lo es.

En los comienzos, hacia 1994, los primeros medios digitales no se paran a contemplar la importancia de la documentación. Su principal problema es trasformar la información del periódico impreso y publicarla de forma digital. Sin embargo, parte del proceso técnico que luego se usará en los centros de documentación digital ya se había producido. En efecto, una parte importante de los periódicos españoles, entre ellos ABC, La Vanguardia o El Periódico de Cataluña ofrecían sus contenidos a través de CD-ROM, uno cada tres meses. De esta forma se podía acceder a una gran cantidad de información que ya estaba digitalizada. Este servicio fue y sigue siendo importante para las bibliotecas. Pero desde el punto de vista empresarial no fue tan rentable como los editores de prensa pensaban. Aun así se produjo entonces una gran paradoja en una sociedad de la información que demandaba mayor actualización. Los CD-ROM son soportes cerrados y había que esperar días o meses hasta que llegaba el siguiente para poder hacer una consulta.

Al mismo tiempo que los periódicos digitales tienen presencia en Internet, la documentación comienza a hacerse un hueco. Pero es preciso separar la doble función en la que actúan los servicios documentales. Por un lado, apenas es perceptible. La información requiere tal celeridad que apenas son visibles los apoyos documentales. Se compite en los periódicos digitales con la misma rapidez con la que la radio y/o la televisión ofrecen la información. Así pues, en los comienzos no hay documentalistas al lado de los redactores que elaboran la información. Por otro lado, se requiere la conservación de la información que ya ha sido publicada. Esta tarea, habitual para un documentalista en los medios impresos, pierde valor en el ámbito digital ya que se encarga de realizarlo un informático, que es quien genera los PDF o cualquier otro documento o programa que los hará visibles para el usuario. Frente a esto ¿qué le queda al documentalista? Como ya se ha reseñado con anterioridad, adentrarse en la red para elaborar informaciones que ofrece al redactor y sobre todo conocer qué sitios de Internet ofrecen fuentes de información viables, además de los organismos oficiales que han colocado sus contenidos en la web. Es preciso, por tanto, estudiar y conocer con qué fondos cuenta el documentalista de otros medios de comunicación, que siguen siendo una parte importante en la investigación y uso de fuentes para los periodistas, así como medios de otros países Scire. 11 : 2 (sep.-dic. 2005) 63-77. ISSN 1135-3761. 
que muestran sus contenidos a una sociedad global en la que la información afecta de manera directa a la mayoría de ciudadanos.

\section{La hemeroteca/archivo, el negocio de los periódicos digitales}

A lo largo de estos diez últimos años, los fondos documentales de los periódicos digitales han crecido de forma sorprendente. Se ha pasado de periódicos muy sencillos y con pocos contenidos a varias ediciones a lo largo del día. Frente a esta situación el documentalista cuando analiza los documentos se enfrenta a varias versiones informativas, a veces hasta contradictorias, de los contenidos publicados. La tarea más sencilla es conservar, porque las capacidades de almacenamiento son mayores, pero la dificultad llega cuando hay que seleccionar las más importantes.

Es necesario tomar como punto de partida los primeros periódicos digitales. En los comienzos, desde 1994 al año 2000, la mayoría de los periódicos ofrecían como contenidos documentales el periódico digital de los siete últimos días. De esta forma, se crean secciones en la página principal con denominaciones similares a hemeroteca (usado por una gran mayoría), siete días, archivo, siete fechas, centro de documentación, documentación, etc. En esos momentos, eran muy pocas las personas que visitaban los periódicos y muchos menos quienes activaban su hemeroteca. A partir de esa fecha, los periódicos ven cómo crece el número de lectores y también el interés de los mismos por su archivo reciente. Se amplía el plazo a un mes, y luego a varios meses, hasta que algunos periódicos, Avui - http://www.avui.es- por ejemplo, deciden alargar el plazo a varios años. Se produce una simbiosis entre periodismo y documentación, ya que los periódicos digitales contienen información de actualidad y los antecedentes noticiosos de esas informaciones. Además, los lectores/usuarios están acostumbrados a utilizar Internet como método de búsqueda información para su ocio, trabajo o estudio.

Con posterioridad, se produce un fenómeno singular, y es que algunas empresas ofrecen información de varios periódicos a la vez, creando un fondo documental con diversos puntos de vista informativos. Por ejemplo, la empresa catalana Àgora de Traductors Digital (ATD) — http://www.alrasa.com/atd/atdhemer. htm— ofrece informaciones publicadas en Avui, El Periódico y/o La Vanguardia. Existe la posibilidad de consultar en un periódico o en varios, si coincide que la información fue publicada en diferentes medios. Otra de las pioneras en España en el servicio de press-clipping fue MyNewsonline — http://www.mynews.es—, que ofrece un amplio archivo con fondos documentales de los principales periódicos. Los contenidos son de pago. Según la profesora Ángels Jiménez, estos servicios van dirigidos a un amplio sector, entre los que destaca el periodismo, los gabinetes de prensa y comunicación, empresas, instituciones y organismos, intranets, sedes webs corporativas y portales de Internet.

Scire. 11 : 2 (sep.-dic. 2005) 63-77. ISSN 1135-3761. 


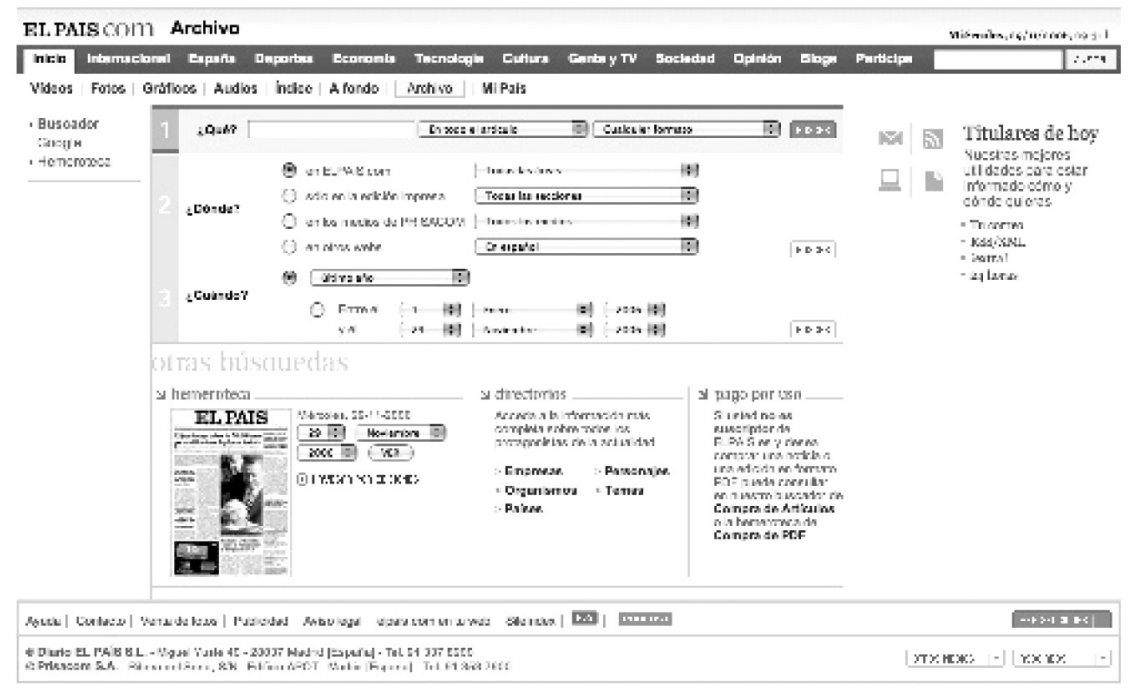

Figura 1. Puerta de entrada al archivo de elpais.es

Mientras los editores estudiaban la posibilidad de cobrar por los contenidos, los periódicos digitales se convirtieron en uno de los principales sitios de reunión en Internet. Así, medios como El Mundo o El País, se sitúan entre los diez primeros lugares de Internet más visitados en España. Desde entonces, los medios pasan por varias etapas hasta la situación actual. La inicial es común para la mayoría, ya que todos apuestan por dejar libre su información. Luego, en una segunda etapa, hay medios mixtos como El Mundo que prefieren dejar libre la mayor parte de la información y ofrecer un plus de calidad para otras informaciones que serán de pago y los que mantienen el acceso totalmente gratis. Y, por último, se produce un cambio importante cuando El País decide cerrar su edición y ponerla de pago.

El caso de elpais.es fue especialmente significativo por el giro radical en Internet cuando la mayoría de los contenidos eran gratis. La versión digital —http://www.elpais.es — apareció el 4 de mayo de 1996, coincidiendo con el XX aniversario de su edición impresa, y desde el primer momento apostó por la gratuidad. Con posterioridad, en el año 2002 cerró sus contenidos y pasó a ser de pago. Esta decisión estaba apoyada, además de en el valor de su información, en la posibilidad que se ofrece al suscriptor de acceder a sus fondos. En este caso, se trata de un cuarto de siglo de la reciente memoria de España. Pero, según algunos expertos, los lectores se acercan a los periódicos para leer las últimas noticias y no para pagar por ellas. Si quieren profundizar compran la versión impresa, que además es más fácil de leer porque las pantallas aún no tienen buenas resoluciones.

Scire. 11 : 2 (sep.-dic. 2005) 63-77. ISSN 1135-3761. 
Solo el archivo puede ser un negocio. En su primer día de Internet se explicaba en la versión impresa, el precio por ejemplar y los servicios del archivo que recibían a cambio. Sin unos buenos fondos, la respuesta hubiera sido menor. Así lo considera Eduardo Menchón, cuando indica que ese es el gran negocio:

Por ello nadie va a suscribirse a elpais.es solo para conocer las últimas noticias. El pago solo tiene sentido para usuarios que por motivos profesionales (periodistas, documentalistas, etc.) deben obligatoriamente tener acceso a ElPais.es y principalmente a su archivo. En el archivo está el negocio. Sin embargo el mensaje con que venden el servicio de pago no se centra en el archivo sino que va a dirigido a los lectores habituales que generalmente solo consultan las últimas noticias y que difícilmente pagarán por el servicio.

Por supuesto, la mayoría de los archivos de prensa digital disponen de potentes motores de búsqueda que ofrecen en unos segundos una búsqueda efectiva. Los resultados pueden presentarse mediante texto completo de todos los artículos buscados o con un resumen de contenidos, más datos bibliográficos y un enlace al texto completo, este ya de pago, como se muestra en la mayoría de los periódicos norteamericanos que desde hace un lustro comercializan sus fondos de Internet.Además, se puede acotar la búsqueda temporal por fechas concretas y diferenciar entre lo más reciente y lo histórico.

La gran mayoría de los periódicos norteamericanos como The New York Times, The Washington Post o USA Today solo cobran por usar el archivo. Esta estrate-

\section{News Search: Archive Search News Search}

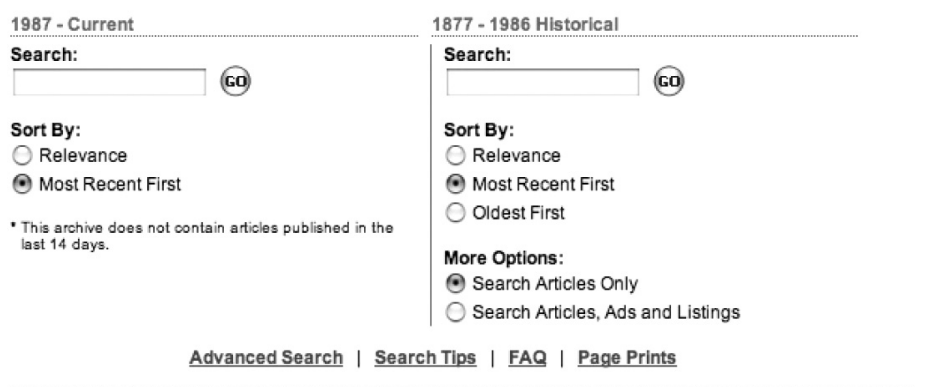

The Terms of Service for this Web site are applicable to your use of the archive. Please read them. Your use of the site indicates your acceptance of these Terms of Service.

About the Archive | Pricing | Account \& Purchases | Help | Terms of Service

(9) 2006 The Washington Post Company

Figura 2. Archivo de The Washington Post que separa las búsquedas actuales de las históricas.

Scire. 11 : 2 (sep.-dic. 2005) 63-77. ISSN 1135-3761. 
gia evita el riesgo de que los lectores se acostumbren a leer otros periódicos en Internet y se pasen también a su edición en papel. Pero además esta estrategia tiene otras consecuencias. La información de calidad, necesaria para la elaboración de trabajos personales o profesionales, se cobra porque conseguir esos datos en otro centro de documentación también implicaría un desembolso. La política correcta de estos medios mezcla una serie de artículos libres (free) que pueden consultar sus lectores y los de pago para quienes necesiten profundizar o abarcar un periodo histórico mayor, como se observa en la figura 2. The Washington Post, y con él el resto de periódicos importantes de Estados Unidos, ofrece una ficha resumen con el título, la sección donde se publicó el artículo, el ISSN o ISBN, el número de palabras del texto y la URL para consultarlo. Además ofrece un abstract mediante el cual el lector puede saber si le interesa comprar o no ese artículo. Por último, se incluye una relación de todos los artículos encontrados, separados por periodo actual e histórico.

Son aún pocos los periódicos españoles que ya han digitalizado todos sus fondos. Por contra, en Estados Unidos hay varios medios que apuestan por el Archivo como una fuente más de ingresos, sobre todo desde que Internet se convirtió en el lugar de trabajo de muchos profesionales que demandan información y que con anterioridad iban a consultar estos datos a las bibliotecas y centros de documentación. Sin embargo, sigue existiendo una fina línea que separa la información gratuita de la de pago. Así, algunos contenidos de pago se pueden encontrar gratis en otro sitio de Internet. Aún hay que clarificar bien qué tipo de información están dispuestos a pagar los lectores. David Fernández propone como recomendación a quien vaya a cerrar los contenidos y cobrar, y también a quien necesite información, lo siguiente: "Debe ser algo que no se encuentre en otro sitio gratis (y menos fuera de Internet). Con calidad y valor añadido suficiente. Diferenciado sensiblemente de otros servicios o contenidos y especializado, es decir, dirigido a un target determinado". Por tanto, los editores de prensa han de mejorar mucho sus contenidos si quieren competir con medios que ofrecen mejores contenidos y más fáciles de encontrar.

Y el futuro más inmediato ¿qué depara? Algunos medios, como The New York Times, creen que a más privilegios más dinero, y para ello han ideado Time Select, un servicio de pago que ofrece contenidos de calidad desde el 19 de septiembre de 2005. Así, por 7,95 dólares al mes o 49,95 al año, los clientes de este servicio podrán acceder hasta a 100 artículos de archivo cada 30 días, crear alertas de noticias personalizadas o leer artículos del periódico y otras publicaciones del grupo Time antes de que se divulguen en las ediciones en papel. Si bien la mayoría de los contenidos siguen en abierto. En definitiva, una apuesta más por los servicios del archivo para rentabilizar la información, que en este caso a través del servicio de alertas incluso puede recibir el lector/usuario antes de que salga publicada en la versión impresa.

Scire. 11 : 2 (sep.-dic. 2005) 63-77. ISSN 1135-3761. 


\section{Conclusiones}

Una década de periódicos en Internet ha servido para que el mundo de la información y el de la documentación se postulen frente a sus necesidades presentes y de futuro, ambos con un mismo fin: servir al usuario mediante la información de actualidad los primeros y entregando contenidos informativos los segundos. Está clara, por tanto, la simbiosis que existe entre el periodista y el documentalista, que ahora es más directa. Así, a la hora de elaborar la información, el periodista sigue demandando documentos al centro que le permitan redactar una información veraz y contrastada. Este paso es decisivo para la creación de un producto de calidad. Una vez que la información ha cumplido su misión de actualidad, el documentalista la retoma para analizarla y ponerla dentro de una base de datos que servirá para que los lectores/usuarios la consulten de forma sencilla y rápida, bien de forma gratuita o de pago. En todo caso, las estrategias documentales siguen actuando en esta doble variante, pensando sobre todo en el rendimiento económico que se puede obtener de la información una vez que ha perdido su inmediatez.

Mientras que en Estados Unidos hace ya varias décadas que algunos medios comercializan la información periodística, con lo cual al llegar Internet solo tuvieron que trasvasarla para dar más opciones a los usuarios, en España ese paso se está produciendo en la actualidad. El negocio de los periódicos digitales —opinan muchos expertos- está en el archivo, porque muy pocos quieren pagar por información de actualidad cuando hay tantos medios que la sirven a cada momento: radio, televisión, correo electrónico, boletines... Es un buen momento para que los periódicos digitales, escasos en recursos financieros, apuesten por los centros de documentación y se encarguen de analizar y estructurar la información y ponerla al servicio de miles de usuarios que necesitan estar informados y sobre todo tener documentos y datos para su trabajo profesional.

\section{Notas}

(1) El Proyecto NewsPad pretendía aplicar la información digital a los nuevos formatos de periódicos digitales incipientes en aquel momento. Tuve la oportunidad de estudiar este proyecto para mi tesis doctoral: Un nuevo concepto de información y documentación en los periódicos digitales (Marcos Recio, 1998). Para ello, visité El Periódico de Cataluña y conocí el proyecto, desde el punto de vista tanto periodístico como documental.

(2) Entrevista con el entonces director técnico de El Periódico de Catalunya el 15 de mayo de 1997 (Marcos, 1998).

\section{Referencias}

Arias, Jon; Marín Murillo, Flora; Merchán Mota, Iker (2000). El diario digital. Análisis de los contenidos textuales, aspectos formales y publicitarios. Barcelona: Bosch, 2000.

Armada, Alfonso (2001). Los gigantes de la comunicación se replantean su expansión en la web. // ABC (9-1-2001).

Scire. 11 : 2 (sep.-dic. 2005) 63-77. ISSN 1135-3761. 
Beaumont, José F. (1996): EL PAIS inaugura su edición electrónica. // El País (3 de mayo de 1996).

Díaz Noci, Javier (2001). La escritura digital. Hipertexto y construcción del discurso informativo en el periodismo electrónico. Bilbao: Servicio Editorial de la Universidad del País Vasco, 2001.

Fernández, David (2005). ¿Cobrar o no cobrar por los contenidos? URL: http://diario red.com/blog/mkt20/archivo/000029.php. Consultado: 2005-09-01.

Jiménez, Àngels. Acceso a información periodística a través de servicios de press clipping [on line]. // Hipertext.net. 1, 2003. URL: http://www.hipertext.net. Consulta: 2005-0901. ISSN 1695-5498 .

Jiménez, Àngels; González, Alfons; Fuentes i Pujol, Eulàlia (2000). Las hemerotecas digitales de la prensa en internet. // El profesional de la información. 9:5 (2000) 15-24. URL: http://intra.pre.gva.es/convera/docpdf_castellano/articulosrevista/iwe/jimenezgonzalez-fuentes2000.pdf. Consultado: 2005-09-01.

Manchón, Eduardo. Diario "El País” online de pago, a examen. URL: http://www.alzado. org/articulo.php?id_art=21. Consultado: 2005-09-09.

Marcos Recio, Juan Carlos (1998). Un nuevo concepto de información y documentación en los periódicos electrónicos. Madrid: Servicio de Publicaciones de la Universidad Complutense, 1998. ISBN: 84-669-1177-4 (tesis doctoral).

Marcos Recio, Juan Carlos (1999). Una nueva concepción de la documentación en los medios electrónicos: retos y nuevas tareas profesionales. Documentación de las Ciencias de la Información. 21 (1999) 113-130.

Marcos Recio, Juan Carlos (1999). La documentación electrónica en los medios de comunicación. Madrid: Fragua, 1999.

Novoa, Olalla. El ataque de los blogs. URL: http://www.elmundo.es/elmundo/ 2005/09/13/comunicacion/1126601442.html. Consultado: 2005-09-14.

Nuño, María Victoria. Organización de los web site de periódicos españoles en internet [on line]. // Hipertext.net. 1, 2003. URL: http://www.hipertext.net. Consultado: 2005-0901. ISSN 1695-5498

Pablos Coello, José Manuel de (2001). La red es nuestra: El "periódico" telemático, la revista "en línea", la radio digital y el "libroweb" cambiarán las formas de comunicación social. Barcelona: Paidós, 2001.

Regoyos, Elena de. Y la cobertura se la lleva...jun blog! URL: http://www.periodista digital.com/periodismo/object.php?o=172281. Consultado: 2005-09-14.

Scire. $11: 2$ (sep.-dic. 2005) 63-77. ISSN 1135-3761. 